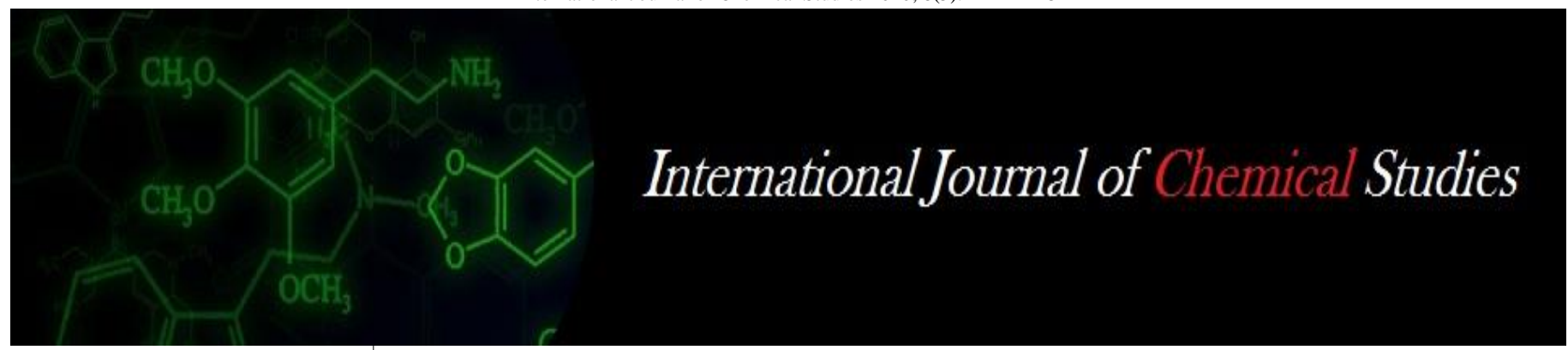

P-ISSN: 2349-8528

E-ISSN: 2321-4902

www.chemijournal.com

IJCS 2020; 8(5): 2221-2225

(C) 2020 IJCS

Received: 04-08-2020

Accepted: 09-09-2020

Reeshu Singh

Department of Plant Molecular

Biology and Genetic

Engineering, N. D. University of

Agriculture and Technology,

Kumarganj Ayodhya,

Uttar Pradesh, India

Sumant Pratap Singh

Department of Plant Molecular

Biology and Genetic

Engineering, N. D. University of

Agriculture and Technology,

Kumarganj Ayodhya,

Uttar Pradesh, India

\section{Ankit Singh}

Department of Crop Physiology

A N D U \& T, Kumarganj

Ayodhya, Uttar Pradesh, India

\section{DK Dwivedi}

Department of Plant Molecular Biology and Genetic

Engineering, N. D. University of Agriculture and Technology,

Kumarganj Ayodhya,

Uttar Pradesh, India

\section{NA Khan}

Department of Plant Molecular

Biology and Genetic

Engineering, N. D. University of

Agriculture and Technology,

Kumarganj Ayodhya,

Uttar Pradesh, India

Corresponding Author:

Reeshu Singh

Department of Plant Molecular

Biology and Genetic

Engineering, N. D. University of

Agriculture and Technology,

Kumarganj Ayodhya,

Uttar Pradesh, India

\section{Screening for sheath blight resistance lines of rice (Oryza sativa $L$.) variety swarna by using of chemical mutagen}

\author{
Reeshu Singh, Sumant Pratap Singh, Ankit Singh, DK Dwivedi and NA \\ Khan
}

DOI: https://doi.org/10.22271/chemi.2020.v8.i5ad.11924

\begin{abstract}
The present investigation was undertaken to identify the resistant lines amongst mutated rice population of the variety swarna induced by the sodium Azide. The variability in disease reaction was observed among mutated rice lines. Out of the total 1000 mutant plants, 47 plants were screened that show low disease index, ranged between 0 to 5 were selected for next M generation. In M2 generation the selected genotypes show differences for disease index, only 12 lines shows resistance in M2 generation in field condition and in humidity chamber condition only 8 lines shows resistance. The number of resistance lines were decreases in humidity condition. Non significant variation in morphological expression and in yield attributes among the selected mutants was also reported. Thus, these lines could be considered a potential source for disease resistance against the sheath blight of rice and could be used further in the crossing programme for development of sheath blight resistant rice variety.
\end{abstract}

Keywords: Screening, sheath blight, chemical, Oryza sativa L.

\section{Introduction}

Rhizoctonia solani Kuhn [Teleomorph: Thanatephorus cucumeris (Frank) Donk] is most widely distributed and destructive pathogen of rice causing sheath blight. It is prevalent in almost all rice growing areas of the world (Dasgupta, 1992) ${ }^{[2]}$ as well as India (Reddy and Reddy, 1986) ${ }^{[14]}$ and has become a major constraint to rice production during the last two decades (Kobayashi, 1997). Due to its wider host range (Roy, 1973; Tsai, 1974; Kozoka, $1975)^{[15,16]}$, it is very difficult to manage through other disease management methods, except resistance breeding. But, the complex genetic nature of resistance to sheath blight and genetic variability of the pathogen increases the difficulty in developing resistant host genotypes, as well as in effectively deploying available tolerant cultivars. Unfortunately, at present, there is no known rice variety which is either immune or possesses high degree of resistance to sheath blight disease in the eastern part of India, only moderate or low level of resistance is present (Dwivedi, 2004) ${ }^{[3]}$. Mutation would be better option for creating variability and to develop resistant genotypes against sheath blight disease of rice. Mutation breeding is one of the most effective ways of inducing genetic variability and creating new mutant lines with desirable traits. Induced mutations have played a vital role for the improvement of rice by developing a large number of semi-dwarf and high yielding varieties around the world.

The Swarna is a popular rice variety in India but it is highly susceptible to sheath blight disease ( $R$. solani). Completely resistant sources to rice sheath blight are yet to be identified from cultivated rice genotypes (Groth and Lee, 2003) ${ }^{[5]}$. Induced mutation breeding may play an important role in identifying individual mutants for rice germplasm improvement (Hu and Rutger, 1992) ${ }^{[8]}$. There are the reports of improvement of different rice genotypes for qualitative (leaf colour, reducing plant height, early maturation period, starch content etc.) and quantitive traits (disease resistance) (Alias et al., 1988; Hadzim et al.,1988) ${ }^{[1,6]}$. Thus, during present investigation we have tried to generate sheath blight resistant genotypes amongst mutated population of rice var. Pusa Basmati-1 that may be effectively used in developing sheath blight resistant rice genotypes in future. 


\section{Materials and Methods}

Plant materials: The seeds of rice variety Swarna were collected from Agricultural Research Farm, Narendra Deva University of Agriculture and Technology, Kumarganj, Faizabad, India. Chemical mutagen sodium azide was used as a mutagen in this experiment. The $0.03 \% \mathrm{NaN}_{3}$ solution were prepared and $\mathrm{pH}$ adjusted with ortho-phosphoric acid. The mutated seeds were grown in nursery and later on healthy seedlings were transplanted in main fields at 21days of growth stage. The genotypes were screened under field conditions and humidity chamber condition in Kharif season for two consecutive years i.e. 20016-17 and 2017-18 for selection of resistant genotypes against $R$. solani. In M1 generation, individual plant represents one single genotype. Some potent mutant genotypes were selected based on the disease evaluation from 10,00 plant population, consisting both mutant and control lines and their seeds were harvested separately. In M2 generation, disease resistance of selected mutants was confirmed by growing progeny to row method. The genotypes depicting very disease index value have been advanced to next generation (i.e. M3 and M4). Control lines of Swana (non-mutated) were grown along with the mutated lines for resistance screening.

Fungal isolate and inoculum preparation: The most aggressive isolate A-1 of Rhizoctonia solani, isolated from the Rice Pathology Laboratory, Indian Institute of Rice Research, Hyderabad (Telangana) India, was taken for resistance screening. After placing sclerotia of $R$. solani onto potato dextrose agar (PDA) under aseptic conditions, cultures were grown at $25 \pm 2^{\circ} \mathrm{C}$ under continuous light. Mycelial bits or immature sclerotia taken from 7-day-old culture were cut and used as inoculum.

\section{Morphological observation}

Observations on plant height, number of tillers were recorded on individual plants of M1 and five plants of M2 generation for screening of potential yielding genotypes.

\section{Experimental design and statistics}

The experimental design was completely randomized design with four replicates. Mean and standard error were calculated from the data optained. Data were analyzed following two way analysis of variance using GENSTAT ( $8^{\mathrm{TH}}$ edition) statistical software package. Where significant $F$ value were obtained, differences between means were separated using Student Newman Keuls test (Alika 2006).

\section{Results}

\begin{tabular}{|c|c|c|c|c|c|c|c|c|c|}
\hline Genotypes & Disease index & Visual rating & Plant height(cm) & Tillers/hill & Genotypes & Disease index & Visual rating & Plant height $(\mathrm{cm})$ & Tillers/hill \\
\hline L1 & 4.32 & 4.08 & 98 & 12 & $\mathrm{~L} 25$ & 3.69 & 2.19 & 104 & 7 \\
\hline L2 & 2.60 & 3.34 & 108 & 14 & L26 & 3.68 & 3.44 & 97 & 8 \\
\hline L3 & 3.54 & 3.48 & 100 & 18 & L27 & 3.68 & 2.19 & 103 & 8 \\
\hline L4 & 4.69 & 4.92 & 99 & 06 & $\mathrm{~L} 28$ & 5.40 & 4.42 & 98 & 13 \\
\hline L5 & 1.50 & 1.32 & 105 & 11 & L29 & 1.22 & 1.67 & 105 & 14 \\
\hline L6 & 3.13 & 3.49 & 100 & 16 & L30 & 3.27 & 3.34 & 89 & 6 \\
\hline L7 & 4.83 & 4.58 & 105 & 5 & $\mathrm{~L} 31$ & 4.53 & 3.59 & 97 & 7 \\
\hline L8 & 2.69 & 1.35 & 107 & 7 & L32 & 1.78 & 1.60 & 90 & 12 \\
\hline L9 & 3.16 & 2.24 & 101 & 6 & L33 & 4.72 & 3.48 & 98 & 12 \\
\hline L10 & 1.23 & 1.62 & 112 & 3 & L34 & 2.46 & 1.98 & 100 & 11 \\
\hline L11 & 4.62 & 3.38 & 104 & 11 & L35 & 4.23 & 3.54 & 98 & 10 \\
\hline L12 & 3.41 & 3.96 & 120 & 7 & L36 & 1.80 & 1.84 & 91 & 6 \\
\hline L13 & 1.68 & 1.39 & 100 & 12 & L37 & 2.82 & 2.56 & 89 & 10 \\
\hline L14 & 4.68 & 4.52 & 108 & 12 & L38 & 3.80 & 4.65 & 97 & 6 \\
\hline L15 & 4.82 & 3.95 & 95 & 7 & L39 & 5.56 & 4.76 & 87 & 8 \\
\hline L16 & 3.90 & 3.58 & 113 & 12 & L40 & 5.60 & 4.52 & 102 & 6 \\
\hline L17 & 4.68 & 3.64 & 110 & 6 & L41 & 1.20 & 1.22 & 108 & 6 \\
\hline L18 & 2.65 & 1.54 & 104 & 4 & L42 & 4.23 & 3.76 & 102 & 11 \\
\hline L19 & 1.89 & 1.87 & 108 & 5 & L43 & 2.62 & 1.49 & 97 & 7 \\
\hline L20 & 1.64 & 1.46 & 108 & 8 & L44 & 4.80 & 4.03 & 105 & 4 \\
\hline L21 & 2.94 & 2.06 & 101 & 7 & L45 & 2.49 & 1.16 & 82 & 10 \\
\hline L22 & 3.28 & 2.58 & 108 & 7 & L46 & 3.34 & 3.06 & 102 & 8 \\
\hline L23 & 3.89 & 3.07 & 40 & 13 & L47 & 5.87 & 4.85 & 96 & 10 \\
\hline L24 & 3.80 & 3.29 & 47 & 7 & Control & 7.75 & 7.67 & 100 & 10 \\
\hline & & & & & CD 5\% & 0.229 & 0.204 & 6.119 & 0.554 \\
\hline & & & & & S.Em \pm & 0.078 & 0.069 & 2.081 & 0.188 \\
\hline & & & & & $\mathrm{CV}$ & 4.394 & 4.449 & 4.216 & 4.245 \\
\hline
\end{tabular}

A total of 1000 mutants rice plant of swarna, 47 rice mutants were screened with better disease resistance from an M1 population and were advanced to next $M$, generation. Observed disease reaction and phenotypic expression among the mutant population consisting of 1000 plants as compared to the control consisting 25 plants. 47 mutant plants were screened based on the field data for disease resistance and the average plant height and number of tillers per hills were also recorded (Table). The disease index of mutated rice population ranged between 0 to 9 whereas in control (untreated) it was calculated between 7 to 9 in M1 generations.

The whole plant population were categorized into different classes based on differential disease response and those showing disease index $>5$ were selected for advancement to next generation (M2). The genotypes showing disease index value zero (0) were discarded because it was assumed that it may be due to disease escape. The panicle of the selected plants were harvested individually, threshed and dried to bring optimum moisture for storage. 
Table 2: Shows the screening of M1 selected rice genotypes in M2 generation in field condition:

\begin{tabular}{|c|c|c|c|c|c|c|c|c|c|}
\hline Genotypes & Disease index & Visual rating & Plant height $(\mathrm{cm})$ & Tillers/hill & Genotypes & Disease index & Visual rating & Plant height $(\mathrm{cm})$ & Tillers/hill \\
\hline L1 & 6.23 & 5.48 & 94 & 11 & L25 & 4.49 & 3.89 & 105 & 9 \\
\hline L2 & 5.60 & 5.34 & 100 & 10 & L26 & 7.48 & 6.49 & 96 & 9 \\
\hline L3 & 3.64 & 3.85 & 105 & 14 & L27 & 5.98 & 4.19 & 108 & 11 \\
\hline L4 & 4.79 & 4.52 & 95 & 10 & L28 & 5.40 & 4.42 & 94 & 14 \\
\hline L5 & 1.70 & 1.82 & 103 & 9 & L29 & 1.82 & 1.97 & 103 & 13 \\
\hline L6 & 3.23 & 3.94 & 110 & 16 & L30 & 4.77 & 3.44 & 89 & 9 \\
\hline L7 & 6.38 & 6.78 & 106 & 8 & L31 & 4.13 & 4.59 & 97 & 6 \\
\hline L8 & 2.69 & 1.35 & 105 & 12 & L32 & 2.48 & 1.64 & 98 & 8 \\
\hline L9 & 3.86 & 2.44 & 98 & 6 & L33 & 4.76 & 4.48 & 98 & 10 \\
\hline L10 & 1.43 & 1.92 & 102 & 10 & L34 & 2.45 & 1.86 & 112 & 8 \\
\hline L11 & 4.82 & 4.78 & 100 & 7 & L35 & 6.63 & 5.94 & 96 & 8 \\
\hline L12 & 6.45 & 5.98 & 107 & 7 & L36 & 1.81 & 1.98 & 95 & 8 \\
\hline L13 & 2.58 & 2.59 & 108 & 12 & L37 & 7.84 & 6.53 & 94 & 12 \\
\hline L14 & 4.87 & 4.55 & 103 & 10 & L38 & 5.80 & 5.65 & 100 & 6 \\
\hline L15 & 7.42 & 6.95 & 98 & 8 & L39 & 6.56 & 5.76 & 82 & 9 \\
\hline L16 & 4.93 & 4.58 & 111 & 12 & $\mathrm{~L} 40$ & 5.60 & 4.52 & 103 & 11 \\
\hline L17 & 5.48 & 4.44 & 97 & 6 & L41 & 3.20 & 3.22 & 98 & 7 \\
\hline L18 & 1.65 & 1.48 & 103 & 9 & L42 & 5.23 & 4.76 & 106 & 12 \\
\hline L19 & 5.99 & 5.47 & 102 & 7 & L43 & 2.62 & 1.49 & 98 & 10 \\
\hline L20 & 1.84 & 1.86 & 107 & 8 & L44 & 7.80 & 6.03 & 111 & 8 \\
\hline L21 & 2.24 & 2.16 & 101 & 7 & L45 & 4.49 & 4.16 & 87 & 7 \\
\hline L22 & 7.48 & 6.18 & 104 & 8 & L46 & 4.74 & 3.06 & 98 & 11 \\
\hline L23 & 5.49 & 5.97 & 87 & 12 & L47 & 5.87 & 4.85 & 102 & 9 \\
\hline L24 & 3.38 & 3.39 & 47 & 7 & Control & 7.95 & 7.67 & 102 & 12 \\
\hline & & & & & CD 5\% & 0.296 & 0.217 & 5.632 & 0.547 \\
\hline & & & & & SEm \pm & 0.089 & 0.064 & 2.013 & 0.163 \\
\hline & & & & & $\mathrm{CV}$ & 4.407 & 4.328 & 4.088 & 4.125 \\
\hline
\end{tabular}

Table 3: Scoring system used to evaluate mutant lines for sheath blight resistance in field condition:

\begin{tabular}{|c|c|c|c|}
\hline Scale & Description & Disease leaf area \% & Genotypes \\
\hline 1 & R & $\begin{array}{c}\text { lesions limited to lower } 20 \% \text { of plant } \\
\text { height }\end{array}$ & L5,L8,L10,L13,,L18,L20,L21,L29,L32L34,L36,L43 (Total-12 genotypes) \\
\hline 3 & MR & 20-30\% disease & L3,L4,L6,L9,L11,L14,L16,L24,L25,L30,L31,L33,L41,L45,L46 (Total-15 genotypes) \\
\hline 5 & MS & $31-45 \%$ disease & $\begin{array}{c}\text { L1,L2,L7,L12,L17,L19,L23,L27,L28, L35,L38.L39,L40,L42,L47 (Total-15 } \\
\text { genotypes) }\end{array}$ \\
\hline 7 & S & 46-65\% disease & L15,L22,L26,L37,L44 (Total-5 genotypes) \\
\hline
\end{tabular}

R- Resistance, MR-Moderate resistance, MS-Moderate susceptible, S- Susceptible

Screening in M2 generation from M1 selected plants in field condition, four types of genotypes were found on the basis of disease reaction of various mutants lines. Out of 47 mutants genotypes, 12 genotypes resistance, 15 genotypes moderate resistance, 15 genotypes moderate susceptible and 5 genotypes were susceptible in M2 generation. This data was recorded by taking mean value of 5 plant from every row of specific genotype. These identified mutant genotypes could be considered being a potential source for disease resistance against the sheath blight of rice.

Table 4: Shows the Screening of M1 selected rice genotypes in M2 generation in humidified chamber

\begin{tabular}{|c|c|c|c|c|c|c|c|c|c|}
\hline Genotypes & Disease index & Visual rating & Plant height(cm) & Tillers/hill & Genotypes & Disease index & Visual rating & Plant height(cm) & Tillers/hill \\
\hline L1 & 6.73 & 6.84 & 94 & 11 & L25 & 5.69 & 4.87 & 105 \\
\hline L2 & 7.60 & 7.48 & 100 & 10 & L26 & 7.47 & 6.79 & 96 & 9 \\
\hline L3 & 4.41 & 4.85 & 105 & 14 & L27 & 5.96 & 4.78 & 108 & 11 \\
\hline L4 & 6.69 & 6.54 & 95 & 10 & L28 & 7.48 & 6.49 & 94 & 14 \\
\hline L5 & 1.77 & 1.89 & 103 & 9 & L29 & 1.88 & 1.93 & 103 & 13 \\
\hline L6 & 3.20 & 3.91 & 110 & 16 & L30 & 6.74 & 6.45 & 89 & 9 \\
\hline L7 & 6.78 & 6.72 & 106 & 8 & L31 & 4.17 & 4.67 & 97 & 6 \\
\hline L8 & 5.89 & 4.75 & 105 & 12 & L32 & 4.47 & 3.69 & 98 & 8 \\
\hline L9 & 4.80 & 2.44 & 98 & 6 & L33 & 6.76 & 5.44 & 98 & 10 \\
\hline L10 & 2.43 & 1.90 & 102 & 10 & L34 & 2.48 & 1.86 & 112 & 8 \\
\hline L11 & 4.84 & 4.28 & 100 & 7 & L35 & 6.63 & 5.94 & 96 & 8 \\
\hline L12 & 6.47 & 6.90 & 107 & 7 & L36 & 2.85 & 1.98 & 95 & 8 \\
\hline L13 & 5.68 & 4.51 & 108 & 12 & L37 & 7.85 & 6.58 & 94 & 12 \\
\hline L14 & 4.57 & 5.52 & 103 & 10 & L38 & 6.83 & 6.60 & 100 & 6 \\
\hline L15 & 7.48 & 6.25 & 98 & 8 & L39 & 7.56 & 6.73 & 82 & 9 \\
\hline L16 & 5.98 & 5.58 & 111 & 12 & L40 & 5.63 & 4.57 & 103 & 11 \\
\hline L17 & 6.47 & 6.45 & 97 & 6 & L41 & 3.78 & 2.23 & 98 & 7 \\
\hline L18 & 1.55 & 1.28 & 103 & 9 & L42 & 7.56 & 6.78 & 106 & 12 \\
\hline L19 & 6.95 & 5.41 & 102 & 7 & L43 & 2.78 & 1.67 & 98 & 10 \\
\hline
\end{tabular}




\begin{tabular}{|l|l|l|l|l|l|l|l|c|c|}
\hline L20 & 3.85 & 3.89 & 107 & 8 & L44 & 7.80 & 6.03 & 111 & 8 \\
\hline L21 & 2.84 & 2.26 & 101 & 7 & L45 & 5.42 & 5.16 & 87 & 7 \\
\hline L22 & 7.58 & 6.68 & 104 & 8 & L46 & 4.74 & 3.06 & 98 & 11 \\
\hline L23 & 6.49 & 5.98 & 87 & 12 & L47 & 6.88 & 6.85 & 102 & 9 \\
\hline L24 & 3.37 & 3.79 & 47 & 7 & Control & 7.65 & 7.88 & 100 & 98 \\
\hline
\end{tabular}

Table 5: Scoring system used to evaluate mutant lines for sheath blight resistance in field condition:

\begin{tabular}{|c|c|c|c|c|}
\hline ScaleDescription & Disease leaf area \% & Genotypes & Total Genotypes \\
\hline 1 & $\mathrm{R}$ & $\begin{array}{c}\text { lesions limited to lower } \\
20 \% \text { of plant height }\end{array}$ & L5,L10,L18,L21,L29,L34,L36,L43 & 8 \\
\hline 3 & MR & $20-30 \%$ disease & L3,L6,L9,L11,L14,L20,L24,L31,L32,L41,L46 & 11 \\
\hline 5 & MS & $31-45 \%$ disease & L1,L4,L7,L8,L12,L13,L16,L17,L19,L23,L25,L27,L30,L33,L35,L38,L40,L45,L47 & 19 \\
\hline 7 & S & $46-65 \%$ disease & L2,L15,L22,L26,L28,L37,L39,L42,L44 & 9 \\
\hline
\end{tabular}

R-resistance, MR-Moderate resistance, MS-Moderate susceptible, S-Susceptible

The 47 selected mutants with low disease index $(>5)$ in M1 generation were selected for screening in M2 generation in humidity condition. In this screening data the only 8 genotypes were resistance and the number of susceptible genotypes were increases from 5 to 9 as compare to M2 generation in field condition. The moderate resistance were 11 and moderate susceptible were 19 in humidity chamber. In this condition the resistance genotypes decreases and number of susceptible were increases as compare to field condition in M2 generation. Thus these identified mutant genotypes could be considered being a potential source for disease resistance against the sheath blight of rice.

\section{Discussion}

These identified mutant genotypes could be considered being a potential source for disease resistance against the sheath blight of rice. Similarly mutantion induced lines of variety Mahsuri were released for blast resistance with improved cooking and eating qualities (Hadzim et al., 1988; Hadjim et al., 1994; Faruq et al., 2003) ${ }^{[6,7,4]}$. The screening of mutant line Zhe-101 selected from the mutant progenies of Indica rice cultivar showed the significant improvement in disease resistance to blast and bacterial blight (Wen-chao et al., 2004) [17]. The elite US rice cultivar "Katy" having " $\mathrm{Pi}$-ta" gene for blast (Magnoporthe grisea) resistance was mutated by using chemical (EMS) and physical mutagens (Fast neutrons and Gamma rays) to explore the molecular basis of disease resistance (Jia et al., 2004) ${ }^{[9]}$. Several researchers have used mutant lines in different crops for disease resistance. Phadvibulya et al., $2009{ }^{[13]}$ obtained YVMD (Yellow vein mosaic disease) resistant okra lines advanced up to 7 th generation. However, only a small portion of the plants of the mutant lines appeared to be resistant throughout the whole growth duration; others eventually exhibited the yellow vein symptoms. Genetic analysis using 72 molecular markers revealed that 45 resistant accessions were indica type. Three accessions were identified two as aromatic, and one each as temperate japonica and tropical japonica. Breeders could use these findings to choose sheath blight resistant accessions for cultivar improvement (Limeng Jia et al., 2011) [11]. Mosaddeque et al., (2008) ${ }^{[12]}$ Conducted that studies on fortyfour test entries of parental lines of rice with one susceptible and one resistant check were screened against sheath blight. Ten lines were resistant, 31 were moderately resistant and 3 showed moderately susceptible reaction at maximum tillering stage.

\section{References}

1. Alias I, Tengku Nazri TZ, Azlan S. Prestasi varieti Muda 2 di kawasan pengairan Muda. Teknol. Padi 1988;4:1-6.
2. Dasgupta MK. Rice sheath blight: The challenge continues. In: Plant Diseases of International importance: Disease of cereals and pulses. Vol.I (Eds. Singh, U.S.; Mukhopadhyay, A.N; Kumar, J. and Chaube, H.S.). Prentice Hall, Englewood Cliffs, New Jersey 1992, pp. 130-150.

3. Dwivedi TL. Rice production in Uttar Pradesh: An Overview. Proceedings of National Symposium of Rice Production in U.P: Key to Food and National Security and Improvement of Farmer's Livelihood, Dec 2004;(1314):1-15.

4. Faruq G, Mohamad O, Hadzim K, Craig MA. Optimization of Aging Time and Temperature of Four Malaysian Rice Cultivars. Pakistan J. Nutr 2003;2:12531.

5. Groth DE, Lee FN. Rice diseases. In Smith, C.W. and Dilday, R.H. (ed.) Rice: Origin, history, technology, and production. John Wiley \& Sons, Inc 2003, pp. 413-436.

6. Hadzim K, Ajimilah NH, Othman O, Arasu NT, Latifah A, Saad A, et al. Mutant Mahsuri: Baka untuk beras bermutu. Teknol. Padi 1988;4:7-13.

7. Hadzim K, Ajimilah NH, Othman O, Arasu NT, Latifah A, Saad A, et al. Mahsuri Mutant: Baka untuk beras bermutu. Teknol. Padi 1994;4:7-13.

8. Hu J, Rutger JN. Pollen characteristics and genetics of induced and spontaneous genetic male sterile mutants in rice. Plant Breeding 1992;129:97-107.

9. Jia Y, Wang Z, Fjellstrom RG, Moldenhauer KAK, Adam MA, Correll FN, et al. Rice Pi-ta gene confers resistance to the major pathotypes of the rice blast fungus in the United States. Phytopathol 2004;94:296-301.

10. Kozaka T. Sheath blight in rice plants and its control. Rev. Plant Prot. Res 1975;8:69-80.

11. Limeng Jia, Wengui Yan, Hesham A, Agrama Kathleen Yeater, Xiaobai Li, Biaolin $\mathrm{Hu}$, et al. Searching for Germplasm Resistant to Sheath Blight from the USDA Rice Core Collection. Crop Science 2011;51:1507-1517.

12. Mosaddeque HQM, Talukder MI, Islam MM, Khusrul Amin AKM, Alam MA. Screening of Some Restorer and Maintainer Hybrid Rice Lines against Sheath Blight (Rhizoctonia solani). J. Soil. Nature 2008;2(1): 23-29.

13. Phadvibulya V, Boonsirichai K, Adthalungrong A, Srithongchai W. Selection for Resistance to Yellow Vein Mosaic Virus Disease of Okra by Induced Mutation. Q.Y. Shu (ed.), Induced Plant Mutations in the Genomics Era. Food and Agriculture Organization of the United Nations, Rom 2009, pp. 349-351.

14. Reddy APK, Reddy CS. Present status of sheath blight disease and its control. In Diamond Jubilee Souvenir 1925-85, ARS, Maruteru (APAU) 1986, pp. 118-127. 
15. Roy AK. Natural occurance of Corticium sasakii on some weeds. Current science 1973;42:842-843.

16. Tsai WH. Assessment of yield losses due to rice sheath blight at different inoculation stages. Jour. Taiwan Agric. Res 1974;23:188-194.

17. Wen-chao Y, Guo-chang S, Jian-long X, Fa-mingY, Xueqin $M$, Qing-sheng J. Breeding of a new Indica Rice Mutant line Zhe-101 for resistance to blast and bacterial leaf blight by space mutation. Chinese J Rice Sci 2004;18(5):415-419. 